\title{
Initial results of a new very rapid rest/ regadenoson stress myocardial perfusion protocol in patients with atrial fibrillation
}

\author{
Lowell Chang ${ }^{1 *}$, Promporn Suksaranjit ${ }^{1}$, Gangadhar Malasana', Allen Rassa', Ganesh Adluru², Krishna Velagapudi ${ }^{1}$, \\ Devavrat Likhite², Alexis Harrison', Brent D Wilson ${ }^{1}$, Christopher J McGann', Nassir F Marrouche', \\ Edward V DiBella ${ }^{2}$
}

From 17th Annual SCMR Scientific Sessions

New Orleans, LA, USA. 16-19 January 2014

\section{Background}

Cardiovascular magnetic resonance (CMR) myocardial perfusion is a well established method for detection of significant obstructive coronary artery disease (CAD). In patients with arrhythmias, standard methods using ECGgating can result in poor image quality. Additionally, with typical stress/rest protocols, a true rest state may not be achieved after administration of regadenoson. However, rest-first may present issues with peri-infarct ischemia and so here we give little time for late enhancement by keeping rest and stress perfusion scans close in time. Given these issues, the two-fold aim of this study is to evaluate the accuracy of a rapid rest-first protocol using an ungated myocardial image pulse sequence.

\section{Methods}

This prospective, single-blinded study included seven atrial fibrillation patients who underwent ungated rest/ stress perfusion imaging and coronary $\mathrm{x}$-ray angiography. Images were acquired using an ungated radial myocardial perfusion sequence $(\mathrm{TR} / \mathrm{TE}=2.2 / 1.2 \mathrm{msec}, 3 \mathrm{~T}$, 20 rays/slice, 5 slices after each saturation pulse, $\sim 2 \times 2$ $\times 8 \mathrm{~mm}$ ), as described in a previous adenosine stressfirst study. Rest/stress protocol was performed in the following fashion: rest image acquisition $(0.05 \mathrm{mmol} / \mathrm{kg}$ gadoteridol, 1.5 minutes), administration of regadenoson $0.4 \mathrm{mg}$ intravenously $(0.4 \mathrm{mg} / 5 \mathrm{~mL})$ to induce hyperemia, 70 second wait, then stress image acquisition
(0.075 mmol $/ \mathrm{kg}$ gadoteridol, 1.5 minutes). CMR images were interpreted $(0=$ normal, $1=$ equivocal, but probably normal, 2 = probable ischemia, 3 = definitely abnormal) and evaluated for quality ( 1 to 5 , lowest to highest quality) by two blinded readers. Perfusion results were condensed to normal (0-1) or disease (2-3). 14 readings for 7 patients were derived from separate reader results. CMR perfusion diagnostic accuracy for the detection of ischemic heart disease was determined by comparison to $\mathrm{x}$-ray angiography with significant lesions defined as $\geq 70 \%$ stenosis or FFR $\leq 0.8$ (Figure 1 ).

\section{Results}

Sensitivity and specificity of this CMR perfusion in the detection of significant coronary lesions were 1 and 0.88 , respectively. Average quality of the readings was $3.8 \pm 0.8$ for both rest and stress perfusion images. Average scan-time for rest/stress perfusion imaging acquisition including time of pharmaceutical injection was $6.5 \pm 4.0$ minutes.

\section{Conclusions}

Initial results for this ongoing rest/regadenoson stress protocol using an ungated myocardial perfusion sequence yielded high sensitivity and specificity for the detection of significant CAD with good image quality. This combination of a novel protocol and an ungated radial sequence addresses the concerns of lingering 


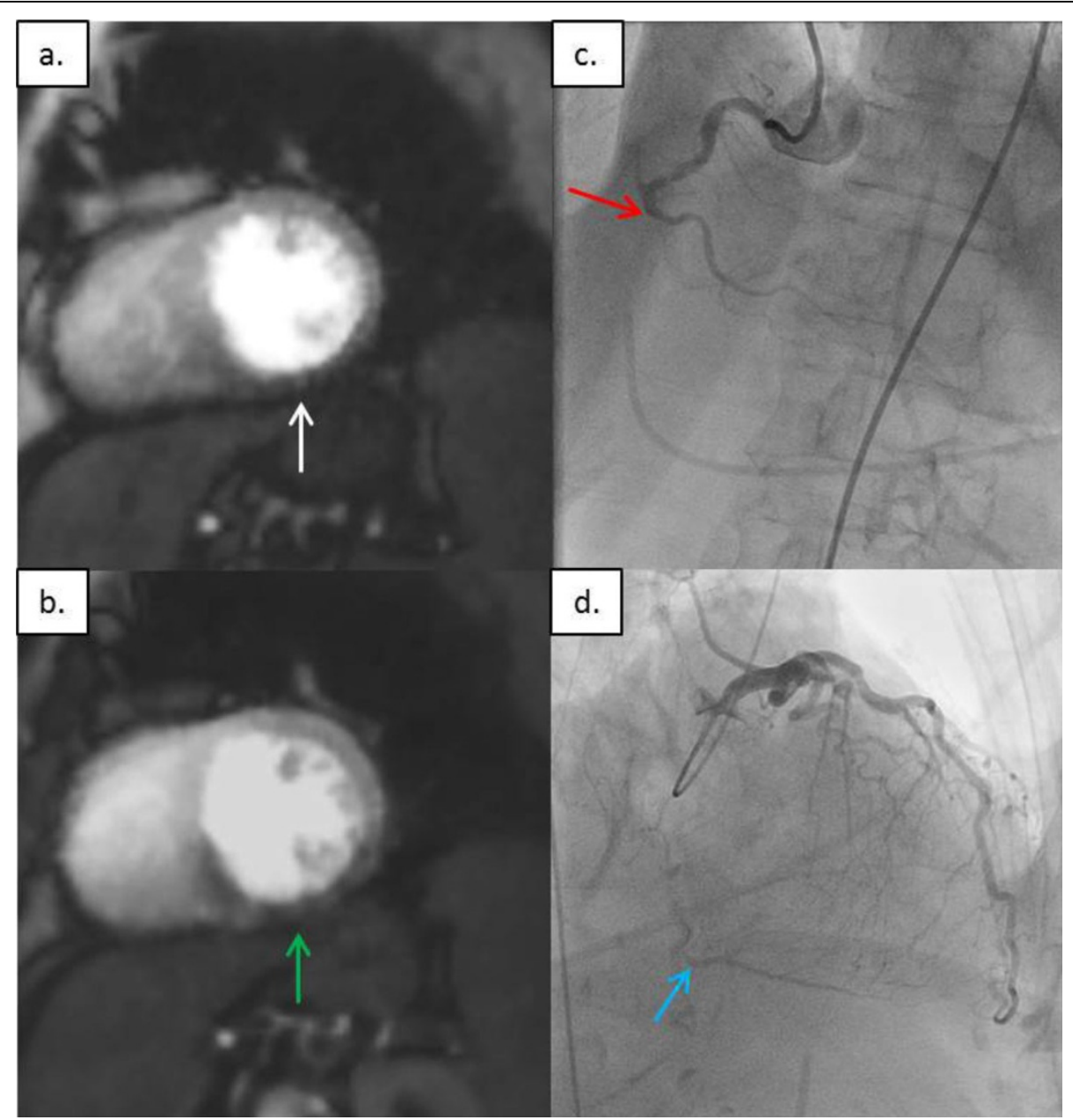

Figure 1 Rest and stress perfusion images showing inferior wall defect with corresponding coronary $\mathbf{x}$-ray angiography. a. Rest perfusion image demonstrating mid inferior wall defect (white arrow). b. Stress perfusion image demonstrating mid inferior wall defect with septal wall extension (green arrow). c. Coronary X-ray angiography demonstrating chronic total occlusion of the mid right coronary artery (red arrow). d. Coronary X-ray angiography demonstrating distal right coronary artery filling via collaterals (blue arrow).

hyperemia with regadenoson along with problematic gating in arrhythmias.

\section{Funding}

Astellas Pharma Inc.

\section{Authors' details}

${ }^{1}$ Cardiology, The University of Utah School of Medicine, Salt Lake City, Utah, USA. ${ }^{2}$ Utah Center for Advanced Imaging Research, The University of Utah School of Medicine, Salt Lake City, Utah, USA.

Published: 16 January 2014

\section{Submit your next manuscript to BioMed Central} and take full advantage of:

- Convenient online submission

- Thorough peer review

- No space constraints or color figure charges

- Immediate publication on acceptance

- Inclusion in PubMed, CAS, Scopus and Google Scholar

- Research which is freely available for redistribution 